\title{
TAREKAT TIJANIYAH DI KALIMANTAN SELATAN
}

\section{Syafruddin*}

\begin{abstract}
Tijaniyah tarekat including one fast-growing tarekat in South Kalimantan. At first the congregation is growing in South Kalimantan in 1995, brought by KH Abmad Ansari is based in the city of Banjarmasin, then spread to various areas in South Kalimantan, Central Kalimantan and even into the Bangka's island. In South Kalimantan there are 21 tarekat and majelis taklim 4 shrines, with the number of followers of about 15,000 people. Tijaniyah congregation has its own characteristics when compared with other tarekat, namely: a) it takes a new format of tarekat, because Ahmad at-Tijani did not require his followers showed the attitude of excessive piety, and he emphasizes the presence of an interpreter intercessor between man and God. It was Abmad at-Tijani itself. b) It has simple and clear wirid; c) Ahmad at-Tijani recognition reaches two positions, namely as a guardian Qutbb alAqthab and khatm al-Waliyah; d) probibits its followers to follow as membership other institutes; e) it has no pedigree. Even if there are genealogy is shorter than the other tarekat, and f) this tarekat probibits its followers to smoke because it is considered as najis.
\end{abstract}

Kata kunci: tarekat Tijaniyah, wirid, zikir

\section{Pendahuluan}

Agama Islam dengan tiga ajaran dasarnya meliputi iman, islam, dan ihsan telah melahirkan berbagai cabang disiplin ilmu. Dimensi keimanan melahirkan ilmu kalam atau ilmu ushuluddin dengan pembahasan pokoknya tentang keesaan Allah; dimensi keislaman melahirkan ilmu fikih dengan pembahasan pokoknya tentang hukum; dan dimensi ihsan melahirkan ilmu tasawuf dengan pembahasan pokoknya tentang kerohanian.

Dalam sumber ajaran Islam terdapat ayat-ayat Alquran maupun sunnah Nabi yang memberi perhatian terhadap masalah kerohanian. Lebih jauh, Alquran juga menjelaskan betapa pengalaman kerohanian Nabi ketika bertemu dengan Malaikat Jibril saat berada di Gua Hira di atas bukit Cahaya (Jabal Nur) dan ketika Nabi di perjalanan dari Masjid al-Haram di Mekkah ke Masjid alAqsa di Palestina (isra) dan kemudian naik ke langit (mikraj) menyaksikan 
tanda-tanda kebesaran Tuhan yang agung tak terkira (al-Isra: 1 dan Najm: 118).

Tasawuf dalam proses pertumbuhan dan perkembangannya dipandang sebagai counter of culture dari perkembangan pemikiran rasional dalam Islam. Pemikiran rasional mendapat dukungan kekuasaan dengan berdirinya kerajaankerajaan besar dalam Islam (kerajaan Bani Umayyah dan Bani Abbas). Ajaran tasawuf tersebut awalnya mendasarkan dari pada perilaku Nabi Muhammad saw., para sahabat dan tabiin, yang bersumber dari Alquran dan sunnah dengan berpijak pada prinsip-prinsip: zuhud, rida dengan kehidupan sederhana, dan motivasi yang intens terhadap keutamaan tingkah laku. ${ }^{1}$

Pertentangan antara penganut syariat di satu pihak, dan penganut tasawuf di pihak lain, terjadi berkepanjangan, bahkan melelahkan. Masing-masing membenarkan keberagamaannya sendiri dan menyalahkan keberagamaan pihak lain. Bentuk-bentuk pertentangan itu terkadang tidak dapat dibenarkan begitu saja. $^{2}$ Persoalan serupa juga terjadi di Kalimantan Selatan. Tarekat-tarekat yang dianut masyarakat dengan doktrin dan ritualnya yang unik sering menimbulkan konflik di antara umat Islam. Hal ini terjadi karena para ulama yang umumnya adalah ulama fikih dan akidah, sering mencurigai, bahkan mengadakan "penelitian" terhadap kebenaran doktrin dan ritual tarekat-tarekat tersebut. Dalam konteks ini bisa dikemukakan beberapa kasus, misalnya kasus $\mathrm{H}$. Jalaluddin versus $H$. Saberan Kacil di Banjarmasin, kasus H. Muhammad Noor di Takisung, dan kasus Qurtubi di Amuntai. ${ }^{3}$ Pada ketiga kasus tersebut, menurut penilaian masyarakat, mereka telah menyimpang dari syariat dan lebih berorientasi kepada wạhdah al-wujüd (tasawuf falsafi).

Pengajian tarekat di Kalimantan Selatan cukup marak, di antaranya pengajian tarekat yang dilakukan oleh tarekat Tijaniyah, tarekat Naqsyabandiyah, dan tarekat Syaziliyah. Pengajian-pengajian tersebut mampu menarik minat masyarakat dari berbagai lapisan, seperti ibu rumah tangga, petani, buruh, pedagang, pegawai negeri, bahkan para guru agama, dari kelas bawah sampai kelas atas, dengan latar belakang dan motivasi yang berbedaberbeda.

\footnotetext{
${ }^{1}$ Wahib, Tasawnf dan Transformasi Sosial: Studi Atas Pemikir Tasawnf Hamka, (Surabaya: IAIN Sunan Ampel, 1997), h. 2.

2Zulkifli, Neo Sufisme di Indonesia Pemikiran dan Perkembangannya, (Palembang: Puslit IAIN Raden Fatah, 1997), h. 5.

${ }^{3}$ M. Zurkani Jahja, Syariat, Sufisme, dan Tarekat: Refleksi Terbadap Beberapa Kasus di Kalimantan Selatan, (Banjarmasin: IAIN Antasari, 1993), h. 18.
} 


\section{Asal-usul Tarekat Tijaniyah di Kalimantan Selatan}

Keberadaan tarekat Tijaniyah di Kalimantan Selatan dibawa oleh K.H. Ahmad Anshari. Beliau adalah anak dari H. Hasan Basri, yang dilahirkan di Kota Banjarmasin Jalan Nagasari pada hari Senin, tanggal 11 Nopember 1956.

Pada usia 6 tahun, tepatnya tahun 1962, ia masuk sekolah dasar di SDN Mawar Jalan Cempaka VII dan selesai pada tahun 1969. Ia kemudian melanjutkan studi ke pesantren Darussalam Martapura atau di Ma'had Istidadul Mualimin. Satu tahun kemudian ia dipindahkan ke kelas 2 Madrasah Tsanawiyah Darussalam. Semenjak itulah ia dibukakan hati oleh Allah bergaul dengan guru-guru tasawuf guna membersihkan batin dan melatih diri agar ingat kepada Allah. Pada usia 13 tahun ia mendapat izin untuk mengamalkan tarekat Syaziliyah dari seorang guru bernama Muhammad Nor yang bertempat tinggal di Dalam Pagar. Tarekat ini diamalkannya selama dua tahun. Kemudian ia masuk ke tarekat Naqsyabandiyah dengan Habib Muhsin bin Ali al-Hindurah asal Sumenep Madura yang kebetulan berada di Banjarmasin.

Ketika berusia 17 tahun, Ahmad Anshari melanjutkan sekolah ke Madrasah Aliyah Darussalam, akan tetapi sebelum menamatkan studinya di Madrasah Aliyah tersebut, tepatnya pada saat duduk di kelas 2, ia keluar dari sekolah itu dengan maksud ingin meneruskan studi ke Makkah al-Mukarramah.

Pada tahun 1974 Ahmad Anshari mendapat panggilan dari Allah swt. untuk melaksanakan rukun Islam kelima dan melanjutkan sekolah di sana selama satu tahun. Sangat disayangkan ia tidak bisa meneruskan sekolahnya dan pulang ke kampung halaman (Banjarmasin) dikarenakan orang tuanya tidak sanggup membiayai. Cobaan ini ia hadapi dengan rida dan hati yang lapang. Untuk mengisi kegiatan ia memilih kerja dan mengaji di kampung, di samping aktif mengamalkan tarekat Naqsyabandiyah.

Selanjutnya, pada tahun $1976 \mathrm{H}$. Ahmad Anshari mendapat panggilan Allah untuk kedua kalinya melaksanakan rukun Islam yang kelima, dan meneruskan studinya. Ia belajar di Mekkah selama 20 tahun (sejak 1976 sampai tahun 1995). Di sana ia mempelajari kitab kuning dengan mengaji duduk. Studinya cukup berhasil, terbukti ia cukup lancar berbahasa Arab, baik nahu maupun syarafnya, dan mampu menerjemahkannya ke dalam Bahasa Indonesia dengan baik.

Pada tahun 1988 K.H. Ahmad Anshari pulang ke Indonesia khusus untuk masuk tarekat Tijaniyah. Ia masuk tarekat Tijaniyah melalui salah seorang tokoh ulama dan tarekat bernama K.H. Badri Masduqi. Pada saat itu di Mekkah ia belum mengetahui dan tidak mendengar adanya tarekat Tijaniyah. 
Untuk mengetahui hal itu ia pulang. Setelah masuk tarekat Tijaniyah, ia kembali ke Makkah.

K.H. Ahmad Anshari masuk tarekat Tijaniyah karena adanya sebuah mimpi bahwa seakan-akan dia berada di salah satu zawiyah tarekat Tijaniyah. Ia belum pernah belajar maupun mendengar tarekat ini dan diberi sebuah kitab Jawâhir al-Ma'anî. Kitab ini menjadi pegangan para pengikut tarekat Tijaniyah. Kitab tersebut memuat amalan atau wirid yang cukup sederhana, tetapi memiliki makna dan manfaatnya sangat luar biasa. Wirid itu memberikan keseimbangan antara istigfar, shalawat dan kalimat tauhid.

Pada tahun 1995, K.H. Ahmad Anshari baru bertemu dengan Syekh Idris al-Iraqi dan berbaiat langsung untuk pengokohan dan pemantapan masuk tarekat Tijaniyah. Pertemuan tersebut tidak direncanakan, karena K.H. Ahmad Anshari sendiri tidak mengenal Syekh dan di mana tempat tinggalnya.

Silsilah tarekat Tijaniyah yang diterima oleh K.H. Ahmad Anshari adalah dari K.H. Badri Masduqi dari Syekh Idris al-Iraqi dari Syekh Muhammad Hafiz al-Misri dari Sayyid asy-Syarif Ahmad Sukayrij al-Marakisyi dari Sayyid asySyarif Ahmad al-Nadalawi at-Tijani dari al-Gauts Asshamadani Sayyidi asySyarif Ali at-Tamasini at-Tijani dari Penghulu seluruh Auliya dari Munriddul Agwats wal Aqthab Maulana Ahmad bin Muhammad bin Muhammad at-Tijani menerima dari al-Habibul Akzham wa Rasulul Akram Muhammad bin Abdillah Sallallahu alaihi wa Sallam secara yakzhah (dalam keadaan jaga), tidak dalam keadaan tidur dan mimpi. ${ }^{4}$

Sanad yang paling dekat adalah pertama, K.H. Ahmad Anshari menerima dari al-Muhaddits Syekh Idris al-Iraqi, dari Syekh Ahmad Sukayrij al-Marakisyi dari Ahmad al-Badalawi dari Syekh Ali at-Tamasini dari Syekh Ahmad at-Tijani dari Rasulullah saw. secara jaga. Kedua, K.H. Ahmad Anshari menerima dari Syekh Ahmad bin Muhammad Hafiz al-Misri dari orang tuanya, Muhammad Hafiz, dari Syekh Abdul Mun'im dari Syekh Ali Maharazim dari Syekh Ahmad at-Tijani dari Rasulullah saw.

Kalau diteliti dari mata-rantai silsilah dan jaringan sanadnya, tarekat Tijaniyah yang dibawa K.H. Ahmad Anshari adalah serumpun dan saling bertalian dengan tarekat Tijaniyah yang ada di Pulau Jawa, karena pada awalnya ia menerima ajaran dan amalan-amalan dari K.H. Badri Masduqi. Sedangkan ajaran dan amalan yang dia terima dari syekh-syekh Tijaniyah lainnya adalah sebagai pengokohan keabsahan amalan tarekatnya.

${ }^{4}$ Lihat, Muhammad bin Abdullah bin Husaini asy-Syafi'i at-Tasfawi At-Tijani, Fath alRabbânî (Kraksaan: Ma’had Badri al-Daja al-Islamiyah, t.th.), h. 156-158. 
Setelah kembali dari menuntut ilmu di Makkah, aktivitas K.H. Ahmad Anshari selanjutnya adalah berkhidmat untuk umat Nabi Muhammad saw., khususnya membina para pengikut tarekat Tijaniyah dengan memberikan pelajaran kepada mereka. Selain itu, beliau juga berusaha mengulang kembali kitab-kitab yang pernah dipelajari di Tanah Suci. ${ }^{5}$

Dari latar belakang pendidikan dan keilmuan K.H. Ahmad Anshari seperti yang telah dipaparkan, wajar jika tarekat Tijaniyah mendapat sambutan hangat di masyarakat, sehingga tarekat ini terus berkembang dan tumbuh subur dalam kehidupan masyarakat. Hasil jerih payah dan kerja keras tanpa pamrih dan ikhlas yang dilakukan K.H. Ahmad Anshari dalam rangka menyebarluaskan ajaran Islam khususnya tarekat Tijaniyah, dapat dilihat dan dirasakan dewasa ini seperti jumlah pengikutnya yang mencapai 15.000 ribu orang dan memiliki 21 majelis taklim.

Lebih lanjut, dari segi kepribadian maupun pengalaman dalam bertarekat, K.H. Ahmad Anshari telah memenuhi kriteria dan persyaratan menjadi seorang mursyid (guru), karena sudah mendapat izin atau ijazah, berarti ia memiliki otoritas serta legalitas kesufian termasuk membimbing, mengayomi, mengawasi, serta mengajarkan jalan hidup tasawuf (ajaran tarekat) kepada pengikut-pengikutnya. Karenanya ia mempunyai tanggung jawab yang cukup berat, di antaranya harus alim, arif, jujur, bijaksana, tawaduk, sabar, dan ahli dalam memberikan bimbingan kepada pengikutnya, baik mengenai amalanamalan yang akan diamalkan maupun masalah-masalah lainnya seperti cara makan, minum, melarang makan banyak dan lain-lain, pandai menyimpan rahasia, tidak sewenang-wenang memerintah dan melarang murid-muridnya, menyediakan tempat berkhalwat, dan lain-lain.

\section{Perkembangan Tarekat Tijaniyah di Kalimantan Selatan}

Tarekat Tijaniyah mulai berkembang di Kalimantan Selatan pada tahun 1995 dibawa oleh muqaddam K.H. Ahmad Anshari yang dipusatkan di Kota Banjarmasin. Ada dua sebab yang melatarbelakangi beliau mengajarkan tarekat ini kepada masyarakat. Pertama, ia mendapat isyarat untuk berpindah ke tarekat Tijaniyah oleh K.H. Badri Masduqi ketika ia menerima pelajaran dan amalanamalan yang kemudian disempurnakan oleh guru Syekh Idris al-Iraqi. Kedua, ketika berziarah ke Mesir dan Maroko pada tahun 1991, ia mendapati pengikut tarekat Tijaniyah sangat banyak di daerah ini dan Allah memberikan

${ }^{5}$ Hasil wawancara dengan K.H. Ahmad Anshari di Banjarmasin. 
kesejahteraan, ketenteraman, serta kedamaian bagi keluarga pengikut, bahkan kepada kota di mana tarekat tersebut diamalkan.

Dengan kedua latar belakang di atas, timbullah keinginan di hati K.H. Ahmad Anshari untuk mengamalkan dan mengajarkan tarekat Tijaniyah. Ia kemudian menjadi muqaddam tunggal wilayah Kalimantan Selatan, Kalimantan Tengah, dan Sumatera Selatan untuk menyebarluaskan ajaran Tarekat Tijaniyah.

Sebelum mengembangkan tarekat Tijaniyah di Kalimatan Selatan, sebenarnya pada tahun 1992 K.H. Ahmad Anshari telah mendapat izin mengembangkan tarekat Tijaniyah di Makkah dengan syarat tidak menampakkan aktivitasnya secara terang-terangan, kecuali Allah sendiri yang menampakkannya. Dengan kehendak Allah akhirnya tarekat Tijaniyah dikenal oleh orang-orang Banjar yang ada di Makkah dan Madinah ketika musim haji. Di Makkah ia mendirikan majelis taklim untuk orang Banjar khususnya, dan masyarakat Muslim Indonesia pada umumnya. Majelis taklim ini dibuka karena ia melihat orang Indonesia banyak yang tidak pandai bahasa Arab, sementara kitab-kitab yang dipakai di dalam majelis-majelis taklim di Makkah berbahasa Arab.

Setelah tiga tahun mengembangkan tarekat Tijaniyah di Makkah, pada tahun 1995, K.H. Ahmad Anshari mendapat perintah dari gurunya, Syekh Idris al-Iraqi, untuk pulang ke kampung halaman dan mengembangkan tarekat ini di Indonesia, terutama di wilayah Kalimantan Selatan.

K.H. Ahmad Anshari termotivasi sekali untuk pulang ke Banjarmasin dan menyebarkan tarekat Tijaniyah di daerah ini. Menurutnya, kondisi umat Islam di daerah ini pada saat itu sudah sangat parah dan rusak, terutama mental/moral dan ibadat. Misalnya setiap orang mengaku beriman kepada Allah swt., namun tidak dibarengi dengan amal saleh yang mendukung pengakuan tersebut. ${ }^{6}$

Pada tahun 1995, K.H. Ahmad Anshari mengembangkan tarekat Tijaniyah di Banjarmasin. Pengikutnya terbatas dari lingkungan keluarga. Pengajian secara berjamaah dilakukan satu kali seminggu di rumahnya sendiri. Beberapa tahun kemudian, pengikutnya bertambah banyak dan menyebar ke pelosok-pelosok kota Banjarmasin, bahkan ke kabupaten-kabupaten di 
Kalimantan Selatan, Kalimantan Tengah dan Sumatera Selatan terutama di Pulau Bangka.

Setelah lima tahun K.H. Ahmad Anshari melaksanakan pengajian tarekat Tijaniyah yang bertempat di rumahnya, tempat pengajian tersebut tidak dapat menampung pengikutnya. Atas prakarsa guru serta dukungan pengikutnya dibangunlah tempat pengajian (zawiyah) yang dapat menampung pengikut dalam jumlah banyak. Bangunan tersebut terdiri atas tiga tingkat yang digunakan sebagai tempat pengaiian, tahlilan, tahfiz dan tadarus Alquran serta kegiatan keagamaan lainnya. Tempat pengajian (zawiyah) ini bukan hanya dikhususkan untuk pengikut tarekat, tetapi dipergunakan juga untuk umum, dengan tujuan untuk lebih meningkatkan nilai-nilai keagamaan bagi umat Islam di daerah ini. Zawiyah ini diberi nama Al-Furqan.

Walaupun tarekat Tijaniyah relatif masih muda usianya di Kalimantan Selatan, tarekat ini sudah maju pesat dalam perkembangannya, jika dibandingkan dengan tarekat lainnya, seperti tarekat Qadiriyah Naqsyabandiyah, Alawiyah, Syaziliyah, Sammaniyah, Junaidiyah, dan Sanusiyah. Hal ini dapat dilihat dari jumlah pengikut yang berhasil diserap berjumlah kurang lebih 15.000 orang serta memiliki 21 majelis taklim yang membantu menyebarkan ajarannya. Semua itu dipusatkan di Kota Banjarmasin beralamat di Jalan Cempaka Sari Raya RT. 74 No. 19 Kelurahan Telaga Biru dan dipimpin langsung oleh K.H. Ahmad Anshari. Majelis Taklim di Kabupaten Hulu Sungai Utara tepatnya di desa Bitin dan Sungai Haji Kecamatan Danau Panggang desa Sungai Luang Kecamatan Babirik dipimpin oleh Aspawi. ${ }^{8}$ Di

${ }^{7}$ Perkembangan tarekat Tijaniyah ini di Pulau Bangka Sumatera Selatan berawal dari banyak orang Pulau Bangka yang masuk pesantren di Barabai Kabupaten Hulu Sungai Tengah dan Martapura kabupaten Banjar, dimulai pada tahun 1908 orang Pulau Bangka datang ke Tahfiz untuk belajar mengaji, siapa orangnya tidak dijelaskan. Kemudian datang lagi yang bernama Makruf untuk belajar ke Martapura, sebelumnya belajar di Barabai dan ia kembali lagi ke Barabai. Mereka ini yang memberikan informasi ke Pulau Bangka, akhirnya banyak orangorang Pulau Bangka masuk pendidikan di dua daerah tersebut. Tapi yang paling banyak di Barabai, termasuk di Pesantren K. Ahmad Nawawi. Pada sisi lain, seorang Banjar yang bernama Abdurrahman Siddiq telah menikahi (tapabini) di Pulau Bangka. Inilah keterkaitan orang Banjar dengan orang Pulau Bangka, Sumatera Selatan (sekarang masuk wilayah Provinsi Bangka Belitung) yang sampai sekarang terus berlanjut. (Hasil wawancara dengan K. Ahmad Nawawi di Barabai).

${ }^{8}$ Kiai Aspawi salah seorang guru/badal untuk Kecamatan Babirik Kabupaten Hulu Sungai Utara, berhubung guru/badal di Desa Bitin Kecamatan Danau Panggang meninggal dunia, untuk mengisi kekosongan di Desa Bitin, Kiai Aspawi juga mengisi pengajian di desa 
kabupaten Hulu Sungai Tengah berpusat di kota Barabai beralamat di Jalan Sarigading desa Banua Binjai Rt. 02 membawahi sebanyak lima desa, yaitu desa Rasau, Mandiangin, Hukung, Kapas dan Kapar, dipimpin Kiai Ahmad Nawawi bin Salam. Majelis taklim di Kabupaten Hulu Sungai Selatan dipusatkan di daerah Pasongkan dan tambangan Bitin Negara di rumah guru K.H. Suni, Kabupaten Banjar di desa Pengaron Jalan Mandarijo Sungai Pinang dipimpin oleh H. Abdul Samad dan Masjid Pancasila Simpang Tiga Sekumpul Martapura dipimpin oleh H. Ahmad. Kabupaten Batola yaitu Anjir Kota Km. 18 RT. 1 No. 13 dipimpin oleh Ibrahim, Kabupaten Tabalong di desa Sulingan, dan Tamban Km 12 Desa Tamban Raya Kecamatan Mekar Sari. Para pengikut tarekat ini juga tersebar di Kabupaten Tanah Laut, Kabupaten Kotabaru dan Kabupaten Tapin. Kemudian tarekat ini berkembang ke Kalimantan Tengah di Sampit dan Palingkau, serta Pulau Bangka Sumatera Selatan. Bahkan menurut K.H. Ahmad Anshari akan dikembangkan di Medan dan Aceh. Dari 21 majelis taklim tersebut, yang mempunyai tempat atau zawiyah sendiri adalah kota Banjarmasin, Desa Bitin Kabupaten Hulu Sungai Utara, Anjir Kabupaten Batola, dan Barabai Kabupaten Hulu Sungai Tengah. Selebihnya menggunakan rumah guru yang mengajar atau pada tempat ibadat seperti mushalla atau masjid dan bisa juga secara bergiliran dari rumah ke rumah pengikutnya.

Dalam mengembangkan tarekat Tijaniyah di Kalimantan Selatan, K.H. Ahmad Anshari mengangkat muqaddam (pemegang wilayah). Mereka boleh membaiat orang yang ingin masuk tarekat ini. Di antaranya adalah pertama, K.H. Suni, salah seorang ulama yang cukup kharismatik di Negara kelahiran tahun 1907. Ia masuk tarekat Tijaniyah ketika naik haji pada tahun 1995 yang langsung dibaiat oleh Syekh Idris al-Iraqi. Walaupun pada saat itu K.H. Suni ${ }^{9}$ ingin sekali berbaiat kepada K.H. Ahmad Anshari, namun karena pada saat itu usianya masih muda, K.H. Ahmad Anshari menolaknya dan untuk membaiat K.H. Suni diserahkan langsung kepada Syekh Idris al-Iraqi. K.H. Suni mulai mengembangkan tarekat ini pada tahun 1996 di daerah sekitar Negara dan tidak meluas ke daerah lainnya, hal ini kemungkinan karena ia sudah tua dan uzur. Kedua, Ahmad Nawawi kelahiran Barabai tahun 1959 masuk tarekat ini

tersebut sehingga ia bolak-balik antara Kecamatan Babirik dan Desa Bitin Kecamatan Danau Panggang. (Hasil wawancara dengan K. Ahmad Nawawi dan Said di Barabai).

${ }^{9}$ K.H. Suni salah seorang ulama dan tokoh masyarakat yang cukup kharismatik, ia membuka pengajian tarekat Tijaniyah di rumah sendiri. Pendidikannya tidak melalui jenjang pendidikan formal, tetapi melalui Pondok Pesantren. (Hasil wawancara dengan K.H. Suni dan Fakrurrazi di Negara). 
melalui K.H. Suni tahun 1997 dan tahun 1999 berbaiat kepada K.H. Ahmad Anshari. Ahmad Nawawi diangkat menjadi muqaddam (pemegang wilayah) pada tahun 2000 dan langsung dipercayakan untuk mengembangkan tarekat Tijaniyah kepada masyarakat sekitar dan santrinya. ${ }^{10}$ Ketiga Ibrahim kelahiran Anjir tahun 1966 masuk tarekat Tijaniyah tahun 1997 dan diangkat menjadi muaqaddam/badal tahun 2000 untuk wilayah Anjir Kota Barito Kuala oleh Ahmad Anshari. ${ }^{11}$ K.H. Ahmad Anshari juga berbaiat kepada K.H. Suni. Hal itu dilakukan, semata-mata untuk mengambil hikmah dari senioritas agar kemuktabarahan dan keabsahan ilmu mereka lebih baik. Di samping menggambarkan solidaritas dan rasa kebersamaan di antara mereka, sehingga sesama pengikut tidak ada perbedaan dan perlakuan khusus. Hal tersebut senada dengan pepatah yang mengatakan, berdiri sama tinggi duduk sama rendah.

Pada muqaddam dan badal tarekat Tijaniyah di daerah ini memberikan kebebasan kepada calon pengikut untuk terlebih dahulu mempelajari mendalam dan mengamalkan wirid dan istigfar maupun shalawat, terkecuali salawat Jaubaratul Kamal. Menurut mereka, salawat Jaubaratul Kamal tidak bisa diamalkan oleh sembarangan orang. Kalau seseorang berkeinginan untuk mengamalkan shalawat itu, harus bersuci, suci badan, pakaian, tempat,d an harus duduk. ${ }^{12}$

Setelah berpikir panjang dan hati yang mantap, calon pengikut tarekat boleh menyatakan masuk (dibaiat) ${ }^{13}$ atau bisa mengurungkan niatnya untuk

${ }^{10} \mathrm{~K}$. Ahmad Nawawi (diberi gelar Ahmad Hiking) adalah salah seorang murid dari K.H. Suni Negara, dan K.H. Ahmad Anshari. Ia adalah pimpinan Pondok Pesantren (Pondok ini tidak memiliki nama) di Kota Barabai, dan memimpin zawiyah tarekat Tijaniyah. Santrisantrinya yang berperan aktif dalam menyebarkan tarekat ini baik di Kota Barabai dan sekitarnya maupun di Pulau Bangka. Ia mengakui bahwa sebagian lulusan Pondok Pesantren ia kurang pandai atau pintar memimpin masyarakat, misalnya dalam memberikan ceramah kurang profesional karena tidak bisa mengemas materi ceramah, sehingga masyarakat merasa bosan untuk menerimanya. Santri K. Ahmad Nawawi berjumlah 25 orang, 15 orang berasal dari Pulau Bangka. Mereka ini menginap di Pondok Pesantren dan 10 orang berasal dari masyarakat sekitarnya. Mereka tidak menginap. Santri tidak dipungut bayaran, kecuali dengan suka rela. (Hasil wawancara dengan K. Ahmad Nawawi dan Said di Barabai).

${ }^{11}$ Hasil wawancara dengan Ibrahim di Anjir Kota.

${ }^{12}$ A. Syinqithy Djamaluddin, Kunci Rabmat Ilahi, (Jawa Timur: Pustaka at-Tijani, 2000), h. 69.

13Proses bertalkin ini dengan cara antara guru (mursyid) dengan calon pengikut tarekat berjabatan tangan dalam posisi duduk sebagaimana duduk tahyat awal dalam salat. Setelah itu, guru (mursyid) mentalkinkan calon pengikut tarekat dengan lafaz; Aku izinkan kamu mengamalkan wirid tarekat Tijaniyah sepanjang hidupmu sampai meninggal dunia. (Hasil wawancara dengan Muhammad Nor dan Muhdi di Banjarmasin). 
tidak menjadi pengikut tarekat. Sebab, untuk syarat masuk tarekat Tijaniyah minimal harus memenuhi tiga persyaratan. Pertama, calon pengikut Tijaniyah tidak mempunyai wirid tarekat lain, karena menurut mereka, jika ia mempunyai wirid lain dikhawatirkan dalam pengamalannya hati menjadi mendua atau bercabang, jika ini terjadi biasanya sering kali menemui kegagalan atau amalan tidak mencapai tujuan yang dikehendaki, apalagi menurut mereka, Allah tidak menyukai hati manusia yang mendua atau bercabang. Kedua, orang yang mentalkinkannya telah mendapat izin yang sah untuk memberikan wirid tarekat Tijaniyah. Ketiga, mendapat izin mengamalkan wirid tarekat tersebut. ${ }^{14}$

Selain ketiga persyaratan di atas calon juga harus sanggup menerima segala ajaran atau wirid yang diberikan oleh muqaddam tarekat ini, karena calon bisa saja ingkar janji. Hal inilah yang sering mereka persoalkan dan ragukan. Baiat itu sesungguhnya adalah janji seseorang kepada Allah untuk mentaati segala aturan dan menjauhi segala larangan-larangan-Nya. Agar janji tersebut betul-betul mendalam, maka perlu disaksikan seorang yang alim, yaitu guru (mursyid). Jadi, baiat sebenarnya bukanlah janji seseorang kepada guru, tetapi janji kepada Allah. Fungsi guru dalam berbaiat tersebut hanyalah sebagai saksi. Kalau ada saksinya janji itu akan selalu diingat oleh yang melakukannya. Oleh karena itu, menjadi pengikut tarekat itu sangat berat dan besar godaannya.

Pengaiian tarekat Tijaniyah di Kalimantan Selatan tidak bersifat eksklusif, maksudnya bukan hanya berlaku bagi kalangan sendiri, tetapi berlaku untuk umum, terutama dalam pengajian, sehingga orang lain juga merasa dihargai dan sadar bahwa Islam adalah untuk semua makhluk.

Dilihat banyaknya jumlah pengikut tarekat Tijaniyah di Kalimantan Selatan sejak mulai berdirinya sampai sekarang, tarekat ini dapat dikatakan mengalami kemajuan dari segi kuantitas. Selain itu, jumlah pengikut yang banyak menggambarkan betapa besar perhatian masyarakat Banjar terhadap ilmu-ilmu keagaman terutama ilmu-ilmu kerohanian atau olah batin. Hal ini didukung oleh penduduk Kalimantan Selatan yang mayoritas beragama Islam dan penganut paham Ahl al-Sunnah wa al-Jama'ah (Sunni), di samping masyarakat Banjar yang suka menghormati kiai atau ulama dan selalu memegang apa yang difatwakan kiai atau ulama tersebut. Hal ini memudahkan tarekat Tijaniyah dalam beradaptasi dan menjalankan aktivitasnya, sehingga mengalami perkembangan yang cukup pesat.

${ }^{14}$ Fauzan Fathullah, Tafi al-Quthbul Maktum Sayidul Awliyaa Syekh Abmad at-Tijani dan Tarekatnya at-Tijani, (Banjarmasin: Ikatan Pengamal Kalimantan, t.th), h. 118. 
Begitu pula, K.H. Ahmad Anshari berkeyakinan bahwa tarekat Tijaniyah akan berkembang sesuai dengan yang dikehendaki Allah. Tidak perlu diekspose melalui surat kabar karena akan timbul dengan sendirinya. Ia menambahkan semakin tarekat ini ditantang atau dimusuhi, maka semakin bertambah pengikutnya. Hal ini terbukti bahwa tarekat Tijaniyah sampai sekarang terus bertambah pengikutnya dan tetap eksis di kalangan masyarakat Islam.

Pengikut tarekat Tijaniyah di Kalimantan Selatan berasal dari berbagai strata sosial, seperti pejabat, pegawai negeri, tokoh-tokoh agama, pedagang, dan petani, yang tersebar di seluruh pelosok daerah. Dilihat dari karakteristik pengikut tarekat ini, yang terbanyak adalah dari golongan petani. Tersebarnya pengikut tarekat Tijaniyah dalam berbagai strata sosial, tentunya ikut mendorong kemajuan dan perkembangannya, karena hampir di setiap kabupaten di Provinsi Kalimantan Selatan ada pengikut tarekat tersebut. Keberadaan mereka ini agak sulit dikenali karena mereka tidak memiliki karakteristik tersendiri dalam kehidupan masyarakat, kecuali ketika diadakan pengajian biasanya mereka memakai pakaian yang serba putih. Bagi mereka pakaian serba putih melambangkan kesucian, baik kesucian lahir maupun kesucian batin.

Berbagai kegiatan yang dilakukan pengikut Tijaniyah di atas menunjukkan ciri keaktifannya sebagai neosufisme. Tarekat Tijaniyah tidak mengajarkan kepasifan, kejumudan dan keterbelakangan, tetapi sangat mementingkan kemajuan. Salah satu upaya yang dilakukan ialah kesepakatan pembentukan organisasi yang dapat mengurus administrasi tarekat sehingga seluruh kegiatan dapat berjalan dengan baik dan lancar. Secara teologis, Tijaniyah berpegang teguh pada sumber ajaran Islam. Oleh karena itu, menurut pengikut Tijaniyah ajaran tarekat ini tidak bertentangan dengan syariat. Walaupun ada serangan terhadap ajaran-ajaran Tijaniyah tampaknya berawal dari kesalahpahaman dan kekhilafan karena dalam sufisme terdapat banyak ajaran dan ungkapan simbolis yang membutuhkan pentakwilan. Oleh karena itu, menurut K.H. Badri Masduqi, pertentangan itu bersifat khilafiyah dan bukan masalah akidah. Khilaf atau perselisihan di bidang akidah harus dibendung. Hanya akidah Ahlussunnah yang harus tegak berdiri. ${ }^{15}$

\section{Ajaran Wirid Tarekat Tijaniyah}

${ }^{15}$ Zulkifli, Neo Sufisme..., h. 86. 
Berdasarkan hasil wawancara, wirid tarekat Tijaniyah pada dasarnya sangat sederhana, simpel, dan mudah diamalkan oleh setiap orang. ${ }^{16}$ Wirid tersebut dibagi tiga, yaitu: wirid Lazim, wirid Warifah dan wirid Haylalah. Susunan wirid tarekat ini diuraikan satu per satu sebagai berikut:

\section{Wirid Lazim}

Wirid Lą̧im diamalkan sehari semalam dua kali, yaitu pagi hari, waktunya setelah shalat subuh sampai waktu Dhuha. Apabila ada uzur, waktunya bisa diperpanjang sampai waktu Maghrib. Kedua, sore hari, waktunya setelah shalat Ashar sampai shalat Isya. Orang yang mengamalkan wirid lazim ini akan memperoleh keutamaan, pahala yang besar, dan tidak akan masuk neraka; juga turut bersamanya kedua orang tua, istri-istri, dan anak-anaknya. Jika waktu wirid sudah habis, tapi belum dikerjakan, harus diqada. ${ }^{17}$

Wirid Lazim yang harus dibaca setiap pagi dan sore tersebut adalah sebagai berikut: 1). Membaca istighfar 100 kali, (Astagfirullabal Azim al-lazi la ilaba illa huwal hayyul qayyum); 2). Salawat kepada Rasulullah saw. sebanyak 100 kali. Lafal shalawat boleh apa saja sekalipun dengan singkat, namun yang diutamakan adalah salawat faith; 3). Membaca Haylalah sebanyak 100 kali, (Lailaha illallah). Pada bacaan keseratus ditambah dengan: (Mubammadur Rasulullabi alaibi Salamu Ilabi). ${ }^{18}$ Namun sebelum membaca wirid lazim itu, terlebih dahulu harus diawali mukaddimah dengan membaca surat al-Fatihah dan shalawat Fatih tiga kali.

\section{Wirid Warifah}

Wirid Warifah dibaca dua kali, siang dan malam. Kalau wirid tersebut tidak dikerjakan pada waktu siang, maka bisa dikerjakan pada malam hari, lebih diutamakan. Apabila sehari semalam tidak dikerjakan sama sekali, harus diqada. ${ }^{19}$ Wiridnya adalah sebagai berikut: 1$)$. Membaca istighfar wazifah

\footnotetext{
${ }^{16}$ Hasil wawancara dengan Ibrahim di Anjir Kota.

${ }^{17}$ Hasil wawancara dengan K.H. Ahmad Anshari, H. Samani dan Anshari Arsyad di Banjarmasin. Lihat pula, Sayid Abdullah Dahlan, Tanbih al-Ghafil wa Irsyad al-Mustafid al-'Aqil, Terj. Bahrun Abu Bakar, Tarekat Tijaniyah Suatu Pertanyaan, (Jakarta: Andamera Pustaka. 1987), h. 31; Fathullah, Tafi al-Quthbul Maketum..., h. 137; Bearman PJ., dkk, (et al.), The Encyclopedia of Islam, (Leiden: Brill, 2000), h. 465.

${ }^{18}$ Hasil wawancara dengan K.H. Ahmad Anshari, Bhina Heriwidodo dan Muhdi di Banjarmasin. Lihat pula, At-Tijani, Fath al-Rabbânî..., h. 9.

${ }^{19}$ Hasil wawancara dengan K.H. Ahmad Anshari, Anshari Arsyad dan Muhdi di Banjarmasin. Lihat pula, at-Tijani, Fath al-Rabbânî..., h. 51-52 dan 83-84; Muhammad al-Arabi an-Saih asy Syurqi Umar At-Tijani, Bughyah al-Mustafid Lisyarthi Munyatil Murid, (Dar al Fikr: 1973 M/1393 H), h. 349-350 dan 361.
} 
sebanyak 30 kali, bacaannya, (Astagfirullabal Azim al-lari la ilaha illa buwal hayyul qayyum); 2). Membaca salawat Fatih sebanyak 50 kali; 3). Membaca Haylalah sebanyak 100 kali, (Lailabaillab); 4). Membaca Jauharatul Kamal satu kali; dan 5). Ditutup dengan wirid. Sebelum menggunakan wirid Warifah pengikut tarekat ini terlebih dahulu membaca mukaddimah sebagaimana mukaddimah wirid Lazim.

3. Wirid Haylalab

Waktu wirid Haylalah adalah setelah shalat Ashar pada hari Jumat sampai waktu Maghrib. Apabila seseorang ada uzur dan tidak mengamalkannya sampai waktunya habis, tidak perlu diqada. Wirid haylalah juga didahului dengan membaca surat al-Fatihah, salawat Fatib sebanyak tiga kali, dan wirid baylalah atau membaca Allah tanpa hitungan sampai Maghrib. Kalau sendirian dibaca sebanyak 1600 atau 1500 atau 1200 atau 1000 kali, dan diakhiri dengan: Lailabaillah saidina Mubammadur Rasulullah Saw).

Secara garis besar, ajaran tarekat Tijaniyah meliputi amalan istighfar, shalawat, dan zikir. Selain tiga wirid tersebut ada juga ajaran mengenai ilmu, harta, kerja, dan moral yang disisipkan pada setiap pengajian, karena dalam pengajian tidak saja membaca dan mengamalkan istighfar, shalawat, dan rikir, tetapi juga diisi dengan ceramah agama. Ajaran-ajaran demikian hanya diperoleh melalui mata-rantai hubungan guru-murid. Hal ini menunjukkan betapa ketat dan sistematisnya tarekat ini mempertahankan konsep rabithah, sehingga ajaran-ajarannya disampaikan melalui mata-rantai guru-murid tersebut.

Dalam hal salawat, pengikut tarekat Tijaniyah memiliki jenis salawat yang berbeda-beda. Demikian pula, panjang dan pendeknya tergantung pemberian (ijazah) guru-mursyid, yakni Syekh atau muaqaddam itu sendiri. Menurut pengikut tarekat ini, panjang pendek salawat yang diberikan guru menunjukkan tinggi rendahnya tingkatan seseorang dalam bertarekat. Salawat yang lebih diutamakan untuk diamalkan oleh pengikut Tijaniyah adalah salawat Fatih dan salawat Jaubaratul Kamal.

Kedua salawat itu merupakan salah satu ciri khusus yang membedakan tarekat ini dengan tarekat lainnya. Menurut mereka, salawat Jaubaratul Kamal tidak bisa diamalkan oleh sembarang orang karena kalau seseorang berkeinginan mengamalkan salawat itu harus berzuci, suci badan, pakaian dan tempat, serta harus duduk menghadap kiblat. ${ }^{20}$ Bahkan, menurut pengakuan

${ }^{20}$ Hasil wawancara dengan K.H. Ahmad Anshari, H. Samani, Teguh Sucipto dan Fahrurrazi di Banjarmasin. Lihat pula, Djamaluddin, Kunci Rabmat Ilabi..., h. 69. 
mereka, kalau seseorang berkeinginan membaca atau mengamalkan salawat itu tidak akan mau hafal dan tidak akan mendapat berkah kecuali berbaiat dengan guru atau mursyid terlebih dahulu.

Kata shalawat adalah bentuk jamak dari shalat, yang berarti doa. Shalawat Nabuwah dapat diartikan doa untuk Nabi saw. Walaupun salawat Nabi itu adalah doa untuk Nabi, oleh para pengikut tarekat Tijaniyah diyakini mempunyai khasiat yang bermacam-macam. Pengikut tarekat ini menjelaskan bahwa khasiat membaca salawat ialah menjadikan segala permintaan akan menjadi mudah dikabulkan Allah swt. Allah telah berjanji akan memasukkan ke dalam surga, serta terhindar dari jamahan api neraka bagi yang mengamalkannya. ${ }^{21}$

Bacaan salawat Nabi jumlahnya cukup banyak. Masing-masing salawat itu memiliki khasiat tersendiri. Namun semuanya memiliki watak menyejukkan bagi yang membaca, bagai mendapat siraman air. Hal ini berbeda dengan zikir yang membuat badan terasa panas. Oleh karena itu sebelum membaca zikir seseorang terlebih dahulu harus membaca salawat dan apabila dalam zikir telah terasa panas ia harus kembali membaca salawat.

Pengikut tarekat Tijaniyah disuruh membaca salawat kepada Nabi saw., sebab Nabi Muhammad saw. adalah makhluk yang paling tahu, yang paling makrifat dan yang terdekat dengan Allah swt. Karena itu, dalam menghadap dan menuju wushul kepada Allah swt., serta mendekatkan diri kepada Nabi dilakukan dengan cara memperbanyak membaca dan mengamalkan salawat.

Pembacaan haylalah (La ilaba illallah) dilakukan dengan suara keras atau nyaring jika dibaca berjamaah dan dengan suara yang cukup didengar sendiri kalau dibaca sendirian. Dalam tarekat Tijaniyah membaca dan mengamalkan haylalah mempunyai tingkatan, seperti bagi orang yang baru masuk (orang awam) tarekat ini kalimat baylalah itu hanya dimaknai tidak ada yang berhak disembah kecuali Allah, bagi orang yang sudah hampir matang dalam mengamalkan amalan tarekat ini (sebut saja golongan orang khawas) haylalab dimaknai tidak ada yang bergantung atau bermaksud kecuali Allah, dan bagi orang yang sudah matang dalam pengamalan amalan tarekat ini (sebut saja golongan khawasul khawas) kalimat haylalah dimaknai tidak ada yang dicintai kecuali cinta kepada Allah swt. ${ }^{22}$

${ }^{21}$ Hasil wawancara dengan K.H. Ahmad Anshari, H. Samani, Rosadi dan Anshari Arsyad di Banjarmasin. Lihat pula, Muhammad ibn Umar an-Nawawi al-Bantani, Tanqih al-Qaul al-Hatsits, (Bandung: Trigenda Karya, 1994), h. 65-75.

22at-Tijani, Fath al-Rabbânî..., h. 77. 
Dalam tarekat Tijaniyah mengamalkan kalimat haylalah tidak sampai kepada $h u$. Menurut pengakuan mereka, kalimat La ilaha illallah semulia-mulia dan seafdhal zikir. Kalimat zikir itu banyak ditampilkan dan disebutkan dalam Alquran. Misalnya La ilaha illallah buwal hayul qayyum dan cara mengamalkannya sebagaimana kebanyakan orang bertahlil atau berzikir. ${ }^{23}$ Lain halnya dengan tarekat Qadiriyah, Junaidiyah, Suhrawardiyah, dan tarekat Syatariyah. Tarekattarekat ini dalam membaca dan mengamalkan kalimat La ilaha illallah sampai kepada $h u$, dengan cara mata dipejamkan, kemudian diarahkan tepat ke tengahtengah dada menuju ke arah dalam rasa dan ada juga dipukulkan ke kiri dan ke kanan.

Zikir La ilaba illallah mempunyai pengaruh yang sangat besar pada saat kematian untuk menghapus dan mencuci kesalahan dan dosa-dosa, baik dosa kecil maupun dosa besar, baik dosa yang sedikit maupun dosa yang banyak karena kalimat itu merupakan saksi atas seorang hamba yang beriman, yang syahwatnya telah terkubur, hawa nafsunya terkebiri, hamba yang bertobat setelah melakukan kemaksiatan, kembali setelah berpaling, merendahkan diri setelah masa kesombongan, dan lain-lain. Pada pokoknya, zikir itu merupakan pernyataan penyesalan dan tersendu bersimpuh di hadapan-Nya. Ia diterima lahir dan batin, baik dalam keadaan sepi maupun ramai. Hatinya telah bersih dari segala ketergantungan dan berpaling kepada selain Allah. Kalimat zikir seperti ini yang akan menyucikan seseorang dari dosa-dosanya. ${ }^{24}$

Zikir haylalah itu diamalkan secara rutin pada hari Jumat sore hingga malam harinya secara serentak dilaksanakan di Kalimantan Selatan, dimulai dari pukul 17.00 wita sampai selesai, diisi dengan mukaddimah yang terdiri atas pembacaan surat al-Fatihah dan shalawat Fatih tiga kali. Setelah itu berniat dan diteruskan dengan membaca warifah yaumiyah berisi istighfar 100 kali, shalawat 100 kali, shalawat Fatih 50 kali dan dilanjutkan membaca La ilaha illallah atau membaca Allah tanpa hitungan sampai menjelang shalat Maghrib. Selesai shalat Maghrib dilaksanakan pengajian hukum Islam (bertahkim) dan ditutup dengan bacaan al-Fatihah dan doa sampai menjelang waktu shalat Isya. Setelah shalat Isya, dilaksanakan acara khusus untuk pengikut tarekat Tijaniyah sampai sekitar pukul 21.00 malam, yang diisi amalan-amalan yang telah ditentukan mursyid (guru).

${ }^{23}$ Hasil wawancara dengan H. Ahmad Anshari, Muhdi dan Fahrurazi di Banjarmasin. Lihat pula, at-Tijani , Bughyah al-Mustafid..., h. 393.

${ }^{24} \mathrm{Ibnu}$ Qayyim al-Jauziyah, Al-Fawaid, terj. Munirul Abidin, Al-Fawaid Menuju Pribadi Takwa, (Jakarta: Pustaka al-Kausar, 2000), h. 58-59. 
Wirid tarekat Tijaniyah yang diberikan kepada Ahmad at-Tijani oleh Rasulullah saw., yang terdiri dari tiga unsur itu harus dibaca tertib dan tartil, yaitu istighfar, shalawat (salawat fatih dan salawat Jaubaratul Kamal) dan haylalab (La ilaba illallah). Istighfar, shalawat dan zikir sudah diajarkan oleh Rasulullah saw. baik melalui Alquran maupun sunah agar bisa dilaksanakan oleh seluruh umat Islam dalam mendekatkan diri kepada Allah dan merupakan bagian dari ajaran agama yang urgan, karena ia merupakan tiang yang kuat untuk menuju Allah swt. Seseorang tidak dapat mencapainya kecuali dengan terus menerus mengamalkan wirid tersebut. Agar wirid (istighfar, shalawat, zikir) itu diterima Allah swt. seseorang harus memenuhi persyaratan. Persyaratan melakukan wirid di antaranya suci dari hadas dan najis, menutup aurat, menghadap kiblat, duduk, dilakukan dengan sepenuh hati, rasa takut kepada Allah, merendahkan diri dan dengan suara perlahan cukup didengar sendiri. ${ }^{25}$

Ketiga wirid tersebut mendekatkan diri seseorang kepada Allah swt. karena ia selalu sibuk baik siang maupun malam dengan wirid. Hatinya tidak pernah terlepas dari mengingat Allah, maka ia mencapai kesempurnaan (makrifat) kepada Allah. Dengan demikian, kehidupan seseorang menjadi tenang, tenteram, bahagia dan selamat dunia maupun akhirat, bahkan balasannya surga.

Menurut pengikut tarekat Tijaniyah, apabila seseorang masuk tarekat Tijaniyah dan mengamalkan ketiga wirid (istighfar, shalawat, rikir) tersebut, ia akan ditanggung oleh Ahmad at-Tijani masuk surga tanpa hisab dan siksaan. ${ }^{26}$ Menurut penulis, tanpa masuk tarekat Tijaniyah maupun tarekat yang lainnya, asalkan seseorang mengamalkan secara terus-menerus sepanjang hidupnya ketiga wirid di atas, Allah menjamin orang itu masuk surga dan akan terhindar dari jamahan api neraka. Hal ini sejalan dengan firman Allah swt. dan hadis Rasulullah saw.

Untuk lebih mantapnya pengamalan ketiga macam wirid di atas, seorang pengikut tarekat Tijaniyah harus melaksanakan perintah dan aturan yang harus dipenuhi, yaitu:

1. Peraturan melaksanakan zikir

a. Dalam keadaan normal bacaan zikir harus terdengar oleh telinga si pembaca.

${ }^{25}$ Hamzah Yaqub, Tingkat Ketenangan dan Kebahagiaan Muslim: Tasawuf dan Takarrub, (Jakarta: Atisa, 1992), h. 312.

${ }^{26}$ Hasil wawancara dengan Ahmad Nawawi dan Said di Banjarmasin. Lihat pula, Fathullah, Tafi al-Quthbul Maktum..., h. 95. 
b. Harus suci dari najis, baik badan, pakaian, tempat maupun apa saja yang dibawahnya.

c. Harus suci dari hadas, baik hadas besar maupun hadas kecil.

d. Harus menghadap kiblat dan duduk.

e. Harus menutupi aurat sebagaimana dalam shalat baik bagi pria maupun wanita.

f. Tidak boleh berbicara.

g. Harus ijtimak dalam melasanakan waæifah dan haylalah sesudah Asar hari Jumat apabila di daerahnya ada pengikut.

h. Istibdarul qudwah, yaitu melaksanakan wirid dari awal sampai akhir membayangkan seakan-akan berada di hadapan Ahmad at-Tijani dan yang lebih utama membayangkan berada di hadapan Sayyidul Wujud saw. dengan keyakinan bahwa beliau pembawa dan wushul Ilallah.

i. Mengingat dan membayangkan makna wirid dari awal sampai akhir, kalau tidak bisa, supaya memperhatikan dan mendengarkan bacaan wiridnya. $^{27}$

2. Tata tertib sebelum berzikir

a. Bertobat, yaitu meninggalkan perkataan dan perbuatan serta kehendak yang tidak penting buat dirinya.

b. Suci dari hadas dan kotoran dengan sempurna.

c. Diam dan tenang.

d. Mohon bimbingan kepada Allah swt. melalui Syekh dengan sepenuh hati ketika hendak memulai zikir sampai selesai, seolah-olah dirinya ditemani Syekh di dalam menghadap Allah,

e. Tahu kalau bimbingan Syekh adalah bimbingan Rasulullah saw. karena bimbingan Syekh juga bimbingan Rasulullah saw.

3. Tata tertib pada waktu berzikir

a. Duduk bersila di atas tempat yang suci seperti hendak mengerjakan salat, lebih sopan lagi kalau duduk seperti dalam shalat. Apabila munfarid harus menghadap kiblat, tapi kalau berjamaah harus membentuk tahlil.

b. Meletakkan kedua tangan di atas kedua paha.

c. Memakai wewangian, baik di tempat berzikir, badan, dan mulut, serta dianjurkan agar bau-bau yang tidak sedap dijauhkan dari majelis zikir

${ }^{27}$ Hasil wawancara dengan K.H. Ahmad Anshari, Ahmad Nawawi dan Said di Banjarmasin dan Barabai. Lihat pula, Fathullah, Tafi al-Quthbul Maktum..., h. 112. 
sebab malaikat dan jin mukmin tidak menerimanya, kalau para malaikat menjauhkan diri dari majelis zikir, bimbingan dapat terputus.

d. Memakai pakaian bagus, halal dan wangi.

e. Tempat zikir sebaiknya gelap, kalau ada lampu sebaiknya dipadamkan,

f. Memejamkan kedua mata agar hati lebih berkonsentrasi, karena indra lahir terputus dari dirinya.

g. Mendatangkan bentuk guru di hadapannya, sesuai dengan kemampuan.

h. Jujur, yaitu keselarasan batin dan lahirnya.

i. Ikhlas, maksudnya amal perbuatan dilakukan dengan bersih tanpa mengharapkan keuntungan dunia, tidak pula di akhirat, pahala dan kenaikan pangkat melainkan dia semata zikir karena cinta kepada Allah.

j. Berzikir dengan penuh semangat, menggoyangkan kepala ke arah kanan pada ucapan " $L a$ " dikembalikan ke arah dada pada ucapan "ilaba" dan pada ucapan "illallah" ditekan ke hati, yaitu di bawah susu sebelah kiri, alasan hakikat membakar hangus segala kejelekan yang bersarang di dalam hati.

k. Menghayati kandungan setiap zikir yang diucapkan sampai seoleh-olah hatinya berzikir, sementara dia mendengarkannya.

1. Memusnahkan segala yang ada di dalam hati selain Allah dengan kalimat tauhid La ilaha illallah.

4. Tata Tertib Sesudah Berzikir

a. Setelah berzikir dianjurkan agar diam dan tenang menghayati seluruh zikir yang telah diucapkan, memperhatikan kalau ada warid yang datang kepadanya. Bila ada sesuatu warid yang datang dalam sekejap, nilainya melebihi warid yang dicari selama tiga puluh tahun lebih. Agar warid tidak menghilang begitu saja dianjurkan diam dan tenang, serta penuh penghayatan.

b. Bermuraqabah kepada Allah seolah-olah Allah di hadapannya.

c. Harus penuh konsentrasi, baik dalam menerima warid maupun dalam mengamalkannya.

d. Harus selalu mengendalikan diri sampai wirid yang datang bersirkulasi pada seluruh faktornya. Warid sangat efektif membuat hati bersih. menyingkap hijab, dan mematahkan bisikan-bisikan nafsu dan setan.

e. Jangan minum setelah berzikir atau waktu tengah berzikir. Zikir punya kalori yang dapat menimbulkan cahaya, membuat segalanya terang. Tajjali mendatangkan dan membangkitkan kerinduan terhadap Allah. Sedangkan air dapat menghilangkan kalori zikir. Karena itu, bersabar 
agar jangan terburu-buru minum, satu setengah jam setelah berzikir. Lebih lama lebih baik. Bahkan kelompok utama hampir tidak mau minum kecuali sangat terpaksa. ${ }^{28}$

5. Syarat sah mengamalkan wirid

a. Wajib suci dari hadas, baik dengan air atau tayamum sebagaimana ditetapkan dalam syariat.

b. Wajib suci dari najis, baik pakaian, jasad ataupun tempat.

c. Wajib menutup aurat sebagaimana ditetapkan di dalam shalat.

d. Tidak boleh berbicara, mulai awal sampai selesai, kecuali ada uzur. Apabila ada uzur, dima'fu dengan satu atau dua kata pada waktu pertengahan wirid, kecuali karena memenuhi panggilan ayah ibu, maka boleh memenuhinya sesuai dengan keperluan mereka berdua. Sebab, memenuhi panggilan mereka itu disenangi Allah yang Maha Pengasih. Demikian pula, istri boleh memenuhi panggilan suami sesuai dengan kehendak suami.

e. Niat membaca wirid. Pada waktu berniat wajib ditentukan waktunya apakah wirid shabah (pagi) atau wirid masa' (malam). ${ }^{29}$

Ajaran tarekat Tijaniyah memiliki ciri khusus yang membedakan dari tarekat lainnya. Tarekat ini membuat format baru karena Ahmad at-Tijani, pendiri tarekat ini, tidak mengharuskan pengikutnya menunjukkan sikap ketakwaan yang berlebihan dan ritualnya yang rumit. Ia menekankan pentingnya keberadaan juru syafaat antara manusia dan Tuhan. Di zamannya, juru syafaat itu adalah Ahmad at-Tijani sendiri.

Pengakuan Ahmad at-Tijani yang mencapai dua kedudukan tertinggi Qutb al-Aktab dan Al-Khatm al-Wilayah ${ }^{30}$ adalah manifestasi dari tradisi ini. Dua

${ }^{28}$ Fathullah, Tafi al-Quthbul Maktum..., h. 112.

${ }^{29}$ Hasil wawancara dengan Ahmad Nawawi Barabai, H. Suni Negara, serta H. Abu Samah dan H. Tajudinnor Banjarmasin. Lihat pula, Djamaluddin, Kunci Rabmat Ilabi..., h. 91-93.

${ }^{30} \mathrm{al}$-Aqthab artinya beberapa wali qutub. Beberapa wali qutub itu disebut quthbul balad, qathbul jama' dan qatbul khatm. Al-Aqthab itu zahir dalam satu masa dan dari beberapa wali qutub itu ada qutub yang tertinggi di zaman itu disebut wali al-khatm. al-Khatm atau auliya adalah orang yang menjadi standar kewalian. Ia adalah ujung dari hirarki tertinggi dan sekaligus penutup garis kewalian pada zamannya. Ia mencapai kedudukan ini tanpa diketahui oleh orang dengan kemampuan (spiritual) yang tak tertandingi dan tergantikan. Kalau ada wali sesudah itu, wali itu adalah pengikut, sahabat atau pembaru untuknya. Sedangkan khatm al-Auliya adalah wali tertinggi mahabbahnya sejak zaman nabi Adam as sampai akhir zaman dan terbanyak mendapatkan limpahan karunia. Lihat Husaini Hasan at-Thabai At-Tijani, Akwa Adallati wal Barabin, (Mesir: Maktabah al-Qahirah al-Azhar, t.th), h. 47; Ibn 'Arabi, Futubat al-Makiah, (Beirut: Dar al-Fikr, 1994), Jilid III, h. 87. 
kedudukan tertinggi itu sejajar dengan kedudukan Nabi Muhammad saw. dalam hubungannya dengan nabi-nabi dan wali-wali. Jika Nabi Muhammad saw. adalah penutup bagi para rasul sebelumnya, dalam pengertian bahwa beliau adalah rasul terakhir dan menduduki derajat tertinggi di antara seluruh rasul yang pernah diutus ke dunia, maka at-Tijani mengaku sebagai wali penutup, dalam pengertian bahwa ia membawa kesempurnaan kewalian (wilayah) untuk seluruh wali, baik sebelum maupun sesudahnya. Jadi, kalau ada wali sesudahnya, maka derajat wali itu tidak setinggi at-Tijani. Bahkan, pengikut tarekat ini membagi Wali Khatm menjadi dua: khatm auliya' 'ammah dan khatm auliya' khashshah. Khatm auliya' ammah adalah Sayidina Isa ibn Maryam a.s. karena beliau menjadi tanda dekatnya hari kiamat. Sedangkan khatm auliya' khashshah adalah at-Tijani karena ia wali yang menghimpun semua kesempurnaan yang ada pada para wali dan yang memelihara semuanya.

Tampaknya Ahmad at-Tijani terpengaruh oleh teosufinya Ibn 'Arabi, seorang sufi termasyhur dari Andalusia abad ke-13 M. Konon Ibn 'Arabi pernah mengaku bahwa dirinya telah mencapai kedudukan Quthb al-Aqthab dan Khatm al-Wilayah. Hal itu sejalan dengan pengakuan Ibn 'Arabi bahwa khatm alwilayah al-Muhammadiyah nanti adalah seorang bangsawan asal Arab yang hidup sezaman dengannya di Fez. ${ }^{31}$

Sejauh ini, para ulama masih berbeda pendapat tentang apakah seorang wali boleh diketahui kewaliannya atau tidak. Sebagian mereka mengatakan hal itu tidak boleh diketahui, karena seorang wali selalu melihat dirinya dengan rendah hati, jika terlihat sedikit saja dari keramatnya, dikhawatirkan akan menipu dirinya. Hal itu dikarenakan seorang wali selalu merasa takut jatuh dari kedudukan kewaliannya dan bisa membawa akibat yang berbalik kepadanya. Sebagian yang lain mengatakan bahwa seorang wali boleh diketahui bahwa dirinya adalah wali. Mereka tidak mengajukan syarat-syarat bagi kewalian. Yang terpenting adalah tanda-tanda wali itu sendiri. Tanda-tanda wali ada tiga, yaitu: ia selalu sibuk dengan Allah, pelariannya selalu kepada Allah, dan tujuannya hanya kepada Allah. ${ }^{32}$

Kalangan sufi membagi wali menjadi beberapa bagian, ada wali al-gauts yang mempunyai kemauan sendiri dalam segala sesuatu di dunia ini, juga ada empat wali qutub memegangi empat pojok dunia ini atas perintah wali al-gauts. Selain itu, ada wali abdal yang tujuh, masing-masing mempunyai kekuasaan di

${ }^{31}$ Hasil wawancara dengan Ibrahim di Anjir Kota. Lihat pula at-Tijani, Akwa Adallati ..., h. 28-30; Ibn 'Arabi, Futubatu al-Makiah..., h. 87.

32al-Qusyairi, Risalah Qusyairiyah..., h. 261-263. 
satu benua dari tujuh benua atas perintah wali al-gants, ada pula wali mujabak yang memiliki kekuasaan di kota-kota setiap wilayah di kota, dan demikian seterusnya. ${ }^{33}$

Dalam ajaran Islam konsep kewalian ditegakkan di atas agama dan takwa, amal saleh, ibadat kepada Allah dan membutuhkan pertolongan Allah. Pada dasarnya wali tidak bisa menguasai dirinya sendiri (untuk mendatangkan manfaat dan mudarat) maupun untuk menguasai orang lain. Allah swt berfirman, yang artinya: "Katakanlah, sesungguhnya aku tidak kuasa mendatang suatu kemudaratan pun kepadamu dan tidak (pula) suatu kemanfaatan". (Q.S. al-Jinn: 21).

Wali Allah tidak terbatas jumlahnya, siapa saja yang taat kepada Allah dan mengikuti jejak Rasul-Nya akan dijadikan Allah wali. Pangkat wali ini terbuka bagi setiap orang, seperti dikemukakan oleh Hamka: "Semua orang dapat mencapai derajat waliyullah itu, asal dipenuhi persyaratannya". ${ }^{34}$

Ahmad at-Tijani telah mengaku dirinya sebagai wali, tetapi yang sering dipersoalkan adalah kedudukannya sebagai Khatm al-Wilayah sesudah Nabi Muhammad saw. Dalam Islam, setelah Nabi Muhammad saw. ada waliyullah, akan tetapi tidak ada pangkat atau embel-embel tambahan seperti wali penutup/tertinggi maupun bagian-bagian wali tertentu. Semua orang bisa mencapainya asalkan memenuhi persyaratan. Persyaratan seseorang menjadi wali di antaranya beriman dan bertakwa kepada Allah, selalu mendekatkan diri kepada Allah, mengerjakan segala yang difardukan dan disunatkan, tidak rakus kepada dunia dan berakhlak mulia. ${ }^{35}$

Dengan mengaku sebagai wali tertinggi atau wali khashshah dari wali-wali lain dan melepaskan ikatannya dari tarekat-tarekat lain, Ahmad at-Tijani secara implisit menempatkan tarekatnya lebih istimewa dari tarekat lain. Pada gilirannya, klaim ini berubah menjadi semacam doktrin yang melarang pengikut tarekat Tijaniyah berdoa atau memohon berkah dari wali-wali lainnya, seperti menziarahi makam mereka karena takut syirik, mewajibkan pengikutnya mengikatkan hati sepenuhnya kepada syekhnya, yang berarti tidak seorang pun pengikut diperkenankan merangkap keanggotaan dengan tarekat lain.

${ }^{33}$ Hartono Ahmad Jaiz, Gusdur Wali? Menundukkan Tasawnf, (Jakarta: Darul Falah, 2000), h. 90-91; Yusril Ali, Membersibkan Tasawnf dari Syiah, Bidah, dan Khurafat, (Jakarta: Yayasan alAmin, t.th), h. 114-115. h. 108.

${ }^{34}$ Hamka, Tasawnf Perkembangannya dan Pemurniannya, (Jakarta: Pustaka Panjimas, 1984),

${ }^{35}$ M. Faiz al-Math, Puncak Robani Kaum Sufi, Khazanah Perjalanan Spiritual Tokob-Tokoh Islam yang Terpendam, (Jakarta: Pustaka Proressif, t.th), h. 175-176. 
Satu lagi ciri yang membedakan tarekat Tijaniyah dengan tarekat-tarekat lainnya adalah genealogi atau silsilah sanad. Lazimnya dalam tradisi sufi, suatu tarekat mempunyai daftar panjang para syekh. Daftar ini menunjukkan adanya hubungan spiritual antara seorang syekh dengan pendiri tarekat itu. Silsilah berfungsi sebagai legitimasi bahwa ajaran dan wirid tarekat yang bersangkutan dianggap benar-benar otentik berasal dari Rasulullah saw. dan juga dari Allah. Dalam tarekat Tijaniyah tidak ada silsilah sanad yang panjang. Apabila ada, silsilah itu lebih pendek dari yang lazimnya dikenal dalam dunia sufi. Sebab, antara Ahmad at-Tijani, pendiri tarekat Tijaniyah, dengan Rasulullah saw. tidak ada guru lain sebagai pembimbing. Ahmad at-Tijani mengaku "dibaiat langsung" oleh Rasulullah saw.

Tarekat Tijaniyah juga mengajak pengikutnya meninggalkan merokok karena, menurut mereka, merokok merupakan suatu najis, rokok mengandung zat nikotin. Sementara dalam setiap melaksanakan shalat, amalan, atau membaca Alquran seseorang harus bersih dari bau mulut dan najis. Program tarekat Tijaniyah selain menghindarkan manusia dari berbagai penyakit yang ditimbulkannya, juga sejalan dengan program pemerintah Republik Indonesia, misalnya melarang merokok agar masyarakat terhindar dari berbagai penyakit yang ditimbulkannya, di antaranya penyakit jantung, stroke, kanker paru-paru dan kandung kemih, dan impotensi.

Menurut pengakuan pengikut tarekat Tijaniyah ajaran tarekat ini tidak terdapat pertentangan antara syariat dan tarekat, keduanya saling berkaitan satu sama lain. Perbedaan antara syariat dan ajaran tasawuf adalah dalam menerima ajaran. Setelah Nabi wafat, umat Islam menerima ajaran agama Islam dari Alquran dan sunnah, serta ijmak. Para ulama juga melakukan ijtihad yang hasilnya bisa benar atau salah. Masing-masing ulama berijtihad sendiri, misalnya, kaum sufi menentukan sumber ajaran agama dari setiap yang berhembus dan bergerak, maka bermunculan tarekat dengan wiridnya yang berbeda-beda.

\section{Penutup}

Berdasarkan uraian yang telah dipaparkan di muka, dapat diambil kesimpulan sebagai berikut: Pertama, tarekat Tijaniyah mulai berkembang di Kalimantan Selatan pada tahun 1995 dibawa oleh K.H. Ahmad Anshari di Kota Banjarmasin. Dari kota ini tarekat Tijaniyah terus menyebar ke seluruh Kalimantan Selatan, bahkan ke Kalimantan Tengah, dan Pulau Bangka. Tarekat ini memiliki 21 majelis taklim dan 4 zawiyah, dengan jumlah pengikut kurang 
lebih 15.000 orang. K.H. Ahmad Anshari dibantu oleh tiga orang muqaddam atau badal, yaitu K.H. Suni, Kiai Ahmad Nawawi, dan Kiai Ibrahim. Perkembangan pesat tarekat ini tidak terlepas dari berbagai macam sistem dan metode yang mereka gunakan, yaitu: kesederhanaan dan ketegasan aspek ritual, memberikan kebebasan bagi calon pengikut terlebih dahulu mempelajari dan mengamalkan wirid tarekat, memiliki bentuk struktur organisasi keagamaan dan sosial, menganut prinsip tasamuh (toleransi), melaksanakan bimbingan, menganjurkan pengikut berdakwah atau mengajak orang agar masuk tarekat, dan menerapkan persyaratan dan aturan yang wajib ditaati oleh pengikutnya. Kedua, sebagaimana tarekat-tarekat lainnya, tarekat Tijaniyah juga memiliki amalan atau wirid tertentu. Amalan atau wirid tarekat Tijanyah terdiri atas wirid lazim, wirid warifah dan wirid haylalah. Ketiga, Ajaran dan amalan tarekat Tijaniyah memiliki karakteristik tersendiri, antara lain: 1). tarekat ini mengambil format baru karena Ahmad at-Tijani tidak mengharuskan pengikutnya menunjukkan sikap ketakwaan yang berlebih-lebihan, dan menekankan pada kebaradaan juru syafaat antara manusia dengan Tuhan, juru syafaat itu Ahmad at-Tijani sendiri, serta wiridnya sederhana, tegas, dan mudah; 2). pengakuan Ahmad at-Tijani mencapai dua kedudukan, yaitu sebagai wali Quthb al-Aqthab dan Khatm al-Waliyab; 3). tarekat ini melarang pengikutnya merangkap keanggotaan dengan tarekat lain; 4). tarekat ini tidak memiliki silsilah, kalaupun ada silsilahnya lebih pendek dari tarekat lain; dan 5). tarekat ini melarang pengikut merokok karena dianggap najis.

\section{Daftar Pustaka}

Ali, Yunasril, Membersibkan Tasawuf dari Syiah, Bidah, dan Khurafat, Jakarta, Yayasan al-Amin, t.th.

al-Bantani, Muhammad ibn Umar an-Nawawi, Tanqih al-Qaul al-Hatsits, Bandung, Trigenda Karya, 1994.

Dahlan, Sayid Abdullah, Tanbih al-Ghafil wa Irsyad al-Mustafid al-'Aqil, terj. Bahrun Abu Bakar, Tarekat Tijaniyah suatu Pertanyaan, Jakarta, Andamera Pustaka, 1987.

Djamaluddin, A. Syinqithy, Kunci Rabmat Ilabi, Jawa Timur, Pustaka at-Tijani, 2000.

Fathullah, Fauzan, Tafi al-Quthbul Maketum Sayidul Awliya Syekh Ahmad at-Tijani dan Tarekatnya at-Tijani, Banjarmasin, Ikatan Pengamal Kalimantan, t.th. 
Hamka, Tasawuf Perkembangannya dan Pemurniannya, Jakarta, Pustaka Panjimas, 1984.

Hartono, Mulyadi, Mencegah dan Mengatasi Asteoporosis, Jakarta, Puspa Swara, 2001.

Ibn 'Arabi, Mahyuddin, Futubat al-Makiah, Jilid III, Beirut, Dar al-Fikr, 1994.

Jahja, M. Zurkani, Syariat, Sufisme dan Tarekat: Refleksi Terbadap Beberapa Kasus di Kalimantan Selatan, Banjarmasin, IAIN Antasari, 1993.

al-Jauziyah, Ibnu Qayyim, Al-Fawaid, terj. Munirul Abidin, Al-Fawaid Menuju Pribadi Takwa, Jakarta, Pustaka al-Kausar, 2000.

al-Math, M. Faiz, Puncak Rohani Kaum Sufi, Khazanah Perjalanan Spiritual TokobTokoh Islam Yang Terpendam, Jakarta, Pustaka Proressif, t.th.

An-Naisaburi, Abu Qasim Abdul Karim Hawazin al-Qusyairi, Risalah Qusyairiyah fil Ilmu at-Tasawnf, Beirut, Dar al Fikr, t.th.

At-Tijani, Husaini Hasan at-Thabai, Akwa Adallati wal Barabin, Mesir, Maktabah al-Qahirah al-Azhar, t.th.

At-Tijani, Muhammad al-Arabi asy-Syurqi Umar, Bughyah al-Mustafid Lisyarthi Munyah al-Murid, Beirut, Dar al Fikr, 1973 M/1393 H.

At-Tijani, Muhammad bin Abdullah bin Husaini asy-Syafi'i at-Tasfawi, Fathur Rabbani, Kraksaan, Makhad Badri al-Daja al-Islamiyah, t.th.

Wahib, Tasawnf dan Transformasi Sosial: Studi Atas Pemikir Tasawnf Hamka, Surabaya, IAIN Sunan Ampel, 1997.

Yaqub, Hamzah, Tingkat Ketenangan dan Kebahagiaan Muslim: Tasawnf dan Takarrub, Jakarta, Atisa, 1992.

Zulkifli, Neo Sufisme di Indonesia Pemikiran dan Perkembangannya, Palembang, Puslit IAIN Raden Fatah, 1997. 